\title{
A Hybrid Spiral Project Based Learning Model for Microprocessor Course Teaching
}

\author{
Mohammad Tarik M. \\ Computer Engineering Dept. \\ College of Engineering \\ University of Mosul \\ Kirkuk (Alternative location), Iraq \\ Eng.mohammadtarik@gmail.com
}

\author{
Zena Tarik M. \\ College of Engineering \\ University of Mosul \\ Kirkuk (Alter. location), Iraq
}

\author{
Zahraa Tarek M. \\ Mechatronics engineering Dept. \\ College of engineering \\ University of Mosul \\ Kirkuk (Alter. location), Iraq
}

Farah Tareq M.

Computer science Dept.

College of computer and

mathematics science

University of Mosul

Kirkuk (Alter. location), Iraq

\begin{abstract}
High demands for technology increase every day. These demands required expert engineers with high skills to keep up with technology demands. Engineering departments need to responded for this requirement to develop their educational methods. researchers began to develop educational methods and measure their effectiveness. This paper develops an educational method to educate microprocessor course. The educational model mixed the spiral method and project based learning to achieve the desirable goal. Educational activities used in the educational method like lecture, lab, and project. also, virtual lab developed to achieve better learning performance. The proposed educational method evaluated in two ways. First, statistical analysis for students' scores shows significant differences and improvement in the learning outcome. second, students survey shows very positive impact on students learning.
\end{abstract}

Keywords: Hybrid Education Method, Microprocessor Course, Education Methodology, Project Based Learning, Spiral Education Method, Virtual lab, Microprocessor.

\section{INTRODUCTION}

In the current time, our life rapidly changes and continuously develops in every day. This development rises the market requirements where it need high skilled engineering special in technology field. For reaching this goal, it demands to reduce the gap between the teaching information in the course and the technical skilled demands in the market. New educational methodologies for engineering courses organized by researchers to improve the quality of course education [1-4].

Problem based learning methodology is an educational method [5]. This method decrease the gap theory and practice where it is based on real problem [6]. Many literatures used the project based learning [5-9] to educate engineering aspects because PBL used experiments for learning. This method will provide earlier stage of training by these activities during the university education that will lead to better engineers. Engineers will graduate with high rich skills required to face the real life [10]. The PBL have some limitation where the students cannot deal with projects or go in the depth of topics without having the necessary knowledge.
On the other hand, Spiral teaching method [11] Another education method presented by researchers.

This method has a concepts to educate topics at different points of time [12]. At the beginning students learn basics without details, as education progresses, subject details come in and related with the basics to reinforce it.as a result of this, many literatures used spiral teaching method [12-15] to educate engineering courses.

This paper aims to develop hybrid educational method by mixing spiral teaching method and PBL method to achieve better learning performance, better than PBL and spiral teaching method. Two methods mixing eliminate the limitation in the PBL.

The paper organized as follow: (1) Introduction, (2) Spiral Project Based Learning Model, (3) Microprocessor course material, (4) Educational Model for Microprocessor Course, (5) Evaluation and discussion, (6) Conclusion, and (7) references.

\section{Spiral Project Based Learning Model}

To achieve better students learning performance. this paper proposed an educational method called hybrid Spiral project based learning. This hybrid method mixes two learning methodology, projects based learning (PBL) and spiral learning teaching methods as shown in figure 1. The proposed method uses many educational activities like lectures, virtual lab, projects, and lab.

Spiral method constructs the out boundaries of the teaching direction in the proposed educational method. Learning course divided in to number of steps to simplify the course load on the students. Lecturer will teach students each step and then progress to the next in ascending order. The Learning information in the current step based on the learning information in the previous step and so on. in this way students will encounter the topic in each step to expand their skill level and knowledges about the course. Important principles must teach in the beginning steps and other principles come next. Every step contains all of teaching activities mentioned before.

Problem based learning method used inside every step. This method adds dynamic teaching approach to the proposed method in this paper. This method focuses on students in which the 
learning process actively engage students in investigation process to solve problems. Every aspect in each course step can be determined as a problem, this idea capture students interest. Also, it pushes them forward for serious thinking, explore, discussion making with other about the aspects.as a result, Students acquire deeper knowledge about the aspect, and increase the possibility for long term retention of knowledge and skills. Furthermore, it develops students research skills, discussion, communication skills with other. lecturer here responsible for facilitate learning and guide students in developing knowledge about aspects in the right way.

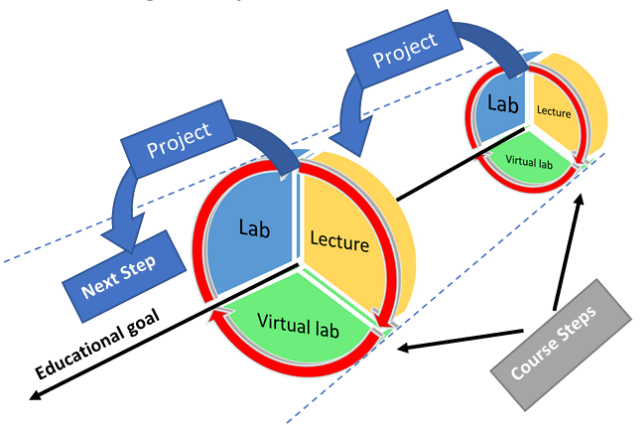

Figure 1: Spiral project based learning scheme.

Closed loop model used in the technic for providing feedback information to enhance the students learning performance. Feedback information can be used by the lecturer for assessing students to determine the weak points in their knowledge and help them to pass over. Also, it used by students to know the difference between their current level and the required achievement level. Students will make more efforts to reduce this amount to reach the desirable level.

\section{Microprocessor Course Materials}

\subsection{Microprocessor Training Kit}

Microprocessor lab handles different activities using development boards. This boards have specific type of processor, different types of peripherals, integrated development environment, and programing interface.

The development board that used in this paper was 8086 microcomputer trainer (MTS-86C). It manufactured by K\&H Taiwan company. This company offers different types of educational training equipment's. MTS-86C board helps the students to understand processor architecture and how deals with processor and peripheral chips. Moreover, it can cover a range of teaching experiments for microprocessor and its peripherals.

The K\&H MTS-86C kit, shown in Figure 2 contains five main parts.8086 CPU, system-user memory, word standard chip sets, input/output devices, and external interface. The 8086 processor could be programed with different types of programing language, low-level and high-level programming languages. In this course, low level programing language used to teach processor programing. Which it helps students to understand the time cycles and the size required for every instruction and program. As a result of this, students will program processors with the most efficient way. Further information about the kit can be found in [16].

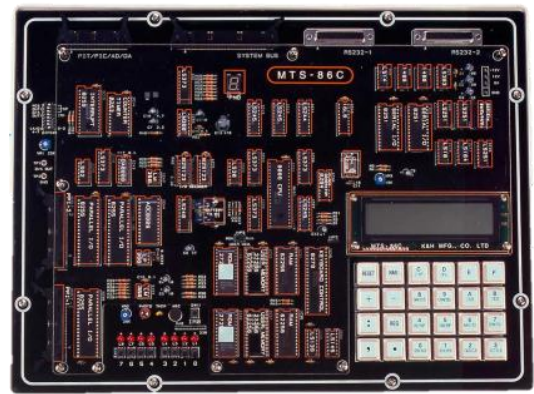

Figure 2: K\&H MTS-86C kit.

\subsection{Virtual Lab for Microprocessor kit}

Many electronic simulation programs are currently more separated than before. These programs simulate electronic components, processors, microcontrollers and also many things. They are currently become one of the electronic design steps to analyze and test the perspective design. Furthermore, it may be used for academic purposes.

These programs provide capability to design rich virtual lab. There are many programs from different companies like Proteus, Mutism, SPICE and etc. Proteus design suit founded by Labcenter Electronics Ltd. It has the capability to simulate electronic components with animated features as LED, oscilloscope, and etc. Moreover, this program simulates many $\mathrm{MCU}$ of different brand PIC, AVR, ARM, and etc. It simulates the MCU by applying the task code to the MCU part in the schematic. Also, it simulates the digital and the analog components with processor in the schematic. The program indicates all types of error due to software issue in the task code or in hardware issue in the design[17]. In the paper, Proteus simulation suit used to design two virtual kits. The first virtual kit contains 8086 processor and supporting elements for the processor as shown in the figure 3 . This one used to teach the students how to deal with processor.

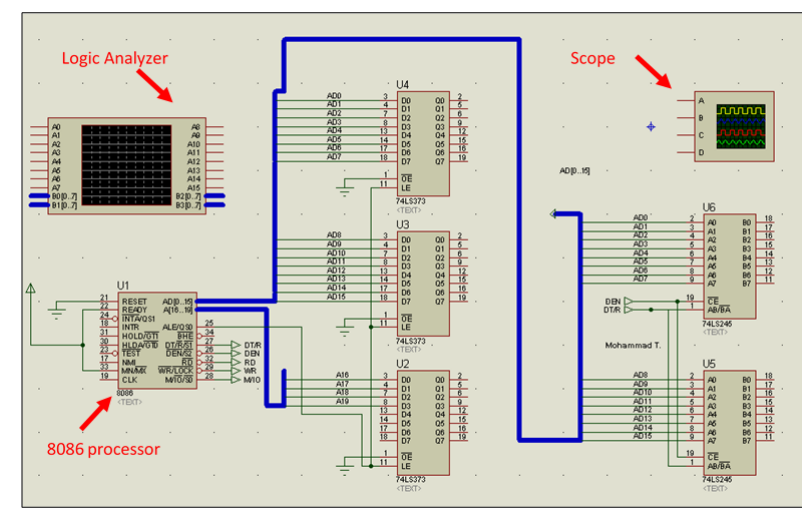

Figure 3: Virtual Kit Part A. 
Second virtual kit contains 8086 processor, peripheral chips, and electronic components as shown in figure 4. Many peripheral chips included like programmable peripheral interface (PPI 8255), programmable interval timer (PIT 8253), and universal synchronous / asynchronous receiver/ transmitter (USART 8251). This virtual kit used to teach students how to make connection between the processor and peripheral chips, and to teach them how to deal with these chips.

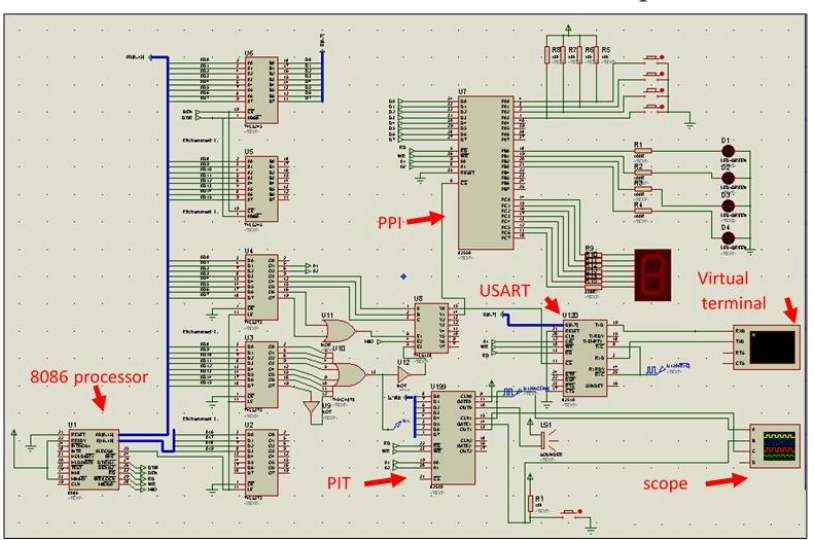

Figure 4: Virtual Kit Part B.

\subsection{Lab Experiments Hands-On}

The proposed hands-on experiments course in this paper effectively concentrated on engaging students during lab. Each experiment in the hands-on course, it designed to lead students through the procedure without significantly need for lecturer supervision. The hands-on contains number of experiments that shown in table 1 . each of them require between one and half hour or 2 hours to complete the procedure. The Overall time for each lab was 3 hours. Each experiment, also, divided in to sub parts with ascending order in complexity, starting with basic principles ending by full target details. At the end of each experiment, students require to perform classwork in the same topic of the experiment.

Table 1: Hands-On Experiments Title.

\begin{tabular}{|l|l|}
\hline \multicolumn{2}{|c|}{ Hands-On Experiments } \\
\hline EX.1 & Basic skills for hardware development \\
\hline EX.2 & Basic skills for software development \\
\hline EX.3 & $\begin{array}{l}\text { Real-Mode Assembly Language Programming } \\
\text { Methodology }\end{array}$ \\
\hline EX.4 & Real-mode processor Programming I \\
\hline EX.5 & Real-mode processor Programming II \\
\hline EX.6 & Basic skills for peripheral hardware \\
\hline EX.7 & Programmable peripheral interface \\
\hline EX.8 & Programmable interval timer \\
\hline EX.9 & $\begin{array}{l}\text { Universal synchronous / asynchronous receiver/ } \\
\text { transmitter }\end{array}$ \\
\hline
\end{tabular}

\section{Educational Model for Microprocessor Course.}

The educational model for microprocessor course centered on the proposed hybrid spiral project based learning in this paper. At first, course goal determined by the lecturer and then the course divided in to number of steps as required. Dividing process insure that every step related to the preceding and the next steps with ascending order. Feedback used to provide information about the progressing to achieve course goal as shown in figure 5 .

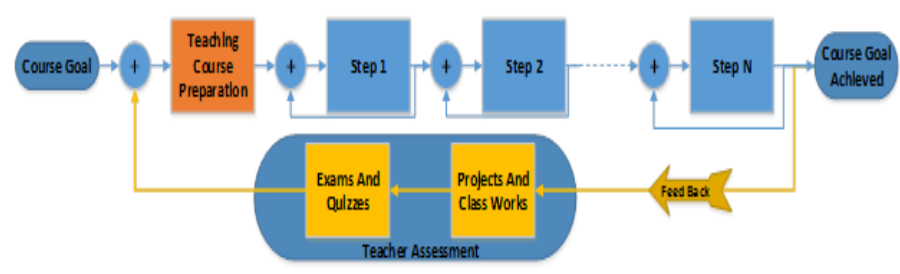

Figure 5: Overall course scheme.

After dividing the course into steps, each step goal determined by the lecturer. Based on that the lecture, virtual lab, lab and project designed to achieve the goal as shown in figure 6 and 7. Each lecture in the course was between one and half hour to two hours. Feedback information for this stage reacquire at least one homework and quiz. After lecture, virtual lab introduces the lab that tight to the step goal that last between half hour to one hour. During virtual lab, a wide discussion area opened between students and lecturer. Lab period required between two hours to two half hours.

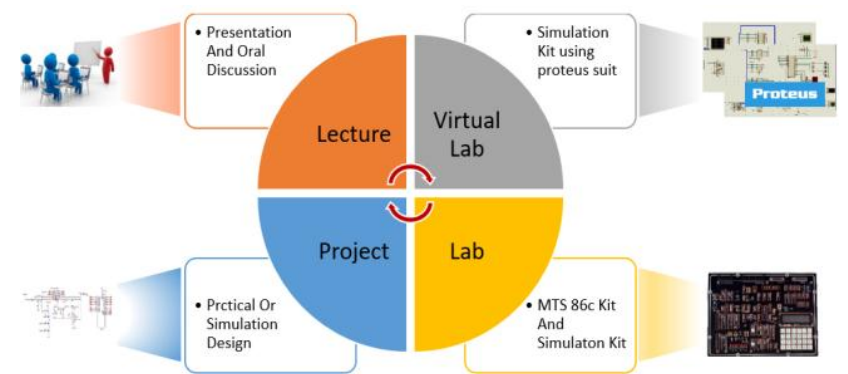

Figure 6: Course Learning Activity.

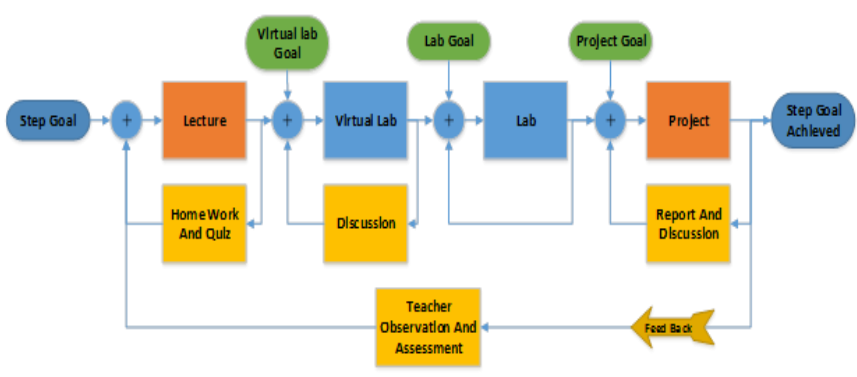

Figure 7: Step scheme.

The lab starts by short lecture to introduce topic then area of discussion between students and lecturer about the topic as shown 8. Students divided to groups each with two to three students. Each group flow the experiment procedure in the hands-on manual. Experiment Procedure focus on students without need for lecturer with ascending complexity order, starting by 
simple topic problem then mid complexity and finally complicated one. After completing the procedure, every group work on classwork which based on fully real-life problem. The lecturer directs the discussion and collect the complex issue that normally similar between students to help them to pass it. Quiz and class work in every lab provide a feedback information to measure students understanding about the topic. All the lab activity based on project based learning. Furthermore, project is the final activity to achieve step goal and move forward for next step. Each project based on real life problem which can be solved by the knowledge from the current step and the preceding steps.one week is the dead time for completing the project. The same cycle performed for each step until the course completed. during the course, every four steps, theoretical and practical exams performed also final theoretical and practical exams performed for all the course.

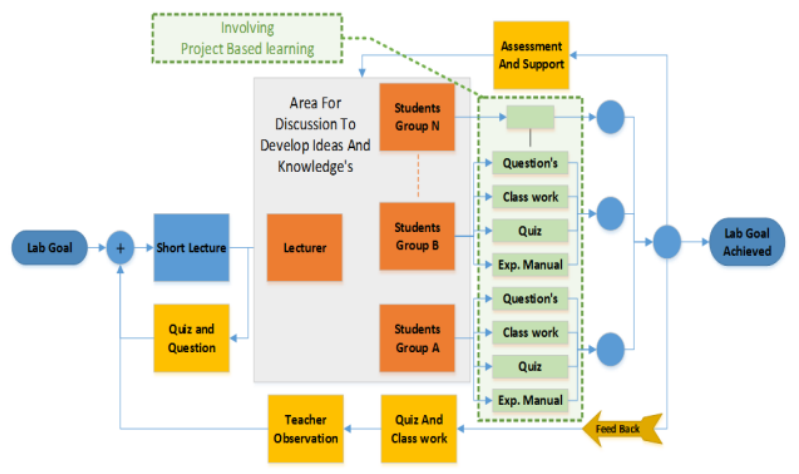

Figure 8: Lab scheme.

\section{Evaluation and discussion}

After course completion, Overall assessment performed to evaluate students' knowledge about the microprocessor course. The proposed method in this paper evaluated in two approaches. First of all, learning methodology evaluation to validate the proposed methodology by collecting students impacts to a number of questions. Secondly, learning methodology effectiveness to validate the effectiveness of methods to learn essential information about the course and how much the students understand about it.

\subsection{Learning Methodology Evaluation}

Online survey performed for students to collect their impact at the end of the course. The online survey divided in to two parts: first part covered the first five steps of the course and the second covered the four last steps. the two parts answered by students to validate the proposed methodology.

Also, the online survey provides a facility for each student to provide his opinion about the methodology. Each question in the survey had number of possible answers to choose. Each student only need to click on the answer he wants. Only one survey for each student accepted. Survey questions shown in table 2 and percentage results for every choice shown in table 3 .

Table 2: Survey questions.

\begin{tabular}{|c|l|}
\hline $\mathbf{S}$ & \multicolumn{1}{|c|}{ Questions title } \\
\hline $\mathbf{1}$ & $\begin{array}{l}\text { Describe your experience with the course learning } \\
\text { methodology? }\end{array}$ \\
\hline $\mathbf{2}$ & $\begin{array}{l}\text { Describe amount of relation between the lecture and the } \\
\text { lab? }\end{array}$ \\
\hline $\mathbf{3}$ & $\begin{array}{l}\text { What do you think about the learning methodology that } \\
\text { used in the course? }\end{array}$ \\
\hline $\mathbf{4}$ & Do you think that the course taught in proper sequence \\
\hline $\mathbf{5}$ & $\begin{array}{l}\text { At end of the course, how do you evaluate the information } \\
\text { you gained in the course? }\end{array}$ \\
\hline $\mathbf{6}$ & Write your opinion about the methodology? \\
\hline
\end{tabular}

Table 3: Survey questions Results.

\begin{tabular}{|c|c|c|c|c|c|}
\hline $\mathbf{S}$ & \multicolumn{5}{|c|}{ Possible Choice and Results } \\
\hline \multirow{2}{*}{$\mathbf{1}$} & Annoying & Boring & Acceptable & Good & Enjoyable \\
& $0 \%$ & $0 \%$ & $19.6 \%$ & $46.65 \%$ & $33.75 \%$ \\
\hline \multirow{2}{*}{$\mathbf{2}$} & Without & WEEK & Acceptable & Good & Complete \\
& Relation & Relation & Relation & Relation & Relation \\
& $0 \%$ & $0 \%$ & $20.25 \%$ & $47.15 \%$ & $32.6 \%$ \\
\hline \multirow{3}{*}{$\mathbf{3}$} & Acceptable & Average & Good & Very & Excellent \\
& $3.55 \%$ & $3.55 \%$ & $14.55 \%$ & Good & $56.05 \%$ \\
& & & & $22.3 \%$ & \\
\multirow{4}{*}{$\mathbf{4}$} & Without & Random & Acceptable & Average & Good \\
& $0 \%$ & Sequence & Sequence & Sequence & Sequence \\
& $0 \%$ & $0 \%$ & $2.85 \%$ & $97.15 \%$ \\
\hline \multirow{5}{*}{$\mathbf{5}$} & Acceptable & Average & Good & Very & Excellent \\
& $3.55 \%$ & $7.15 \%$ & $49 \%$ & Good & $9.85 \%$ \\
& & & & $30.45 \%$ & \\
\hline
\end{tabular}

According to the survey, $33.75 \%$ of students enjoy this experience, $46.65 \%$ of them found it good, $19.6 \%$ of them found it acceptable, and no one found it boring and annoying (question 1). Some of the students mention in question six, that they found this experience improve their thinking capability in solve problem. Result shown in figure 9.a.

About $80 \%$ of students found the relation between the lecture, virtual lab, lab, and project good and excellent (question 2) as shown in figure 9.b. Also ,97\% of the students found the sequence of learning good sequence (question 4) as shown in figure 9.c. from the results of questions two and four, that the proposed learning methodology had properly design and it achieved the desirable mixing between the spiral methods and the PBL.

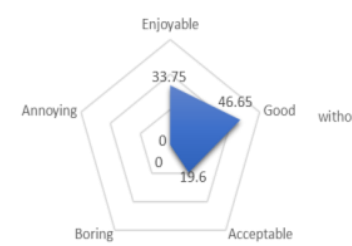

a

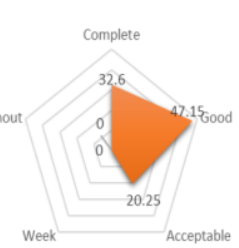

b

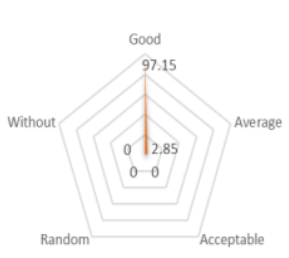

c
Figure 9: Questions Result Chart.

(a)Question 1. (b)Question 2. (c)Question 4. 
About $92 \%$ of students had positive impact to the educational methodology (question 3 ) as shown in figure 10.a. Where about $56 \%$ of them found it excellent .36\% of them found it very good and good. Some of students suggested to increase the lab time to cover more problems to enhance their abilities and improve their knowledges. Also, $89 \%$ of students found the information that the learned in the course, was good and better (question 5) as shown in figure 10.b.

All the statistical analysis of the survey results shown the overall reaction of students' majority to the learning model of microprocessor course was positive. Where the students interested in the course because it contains many real-life problems based on the proposed methodology as a result, the proposed method in this paper validate and can be can be used in deferent engineering course.
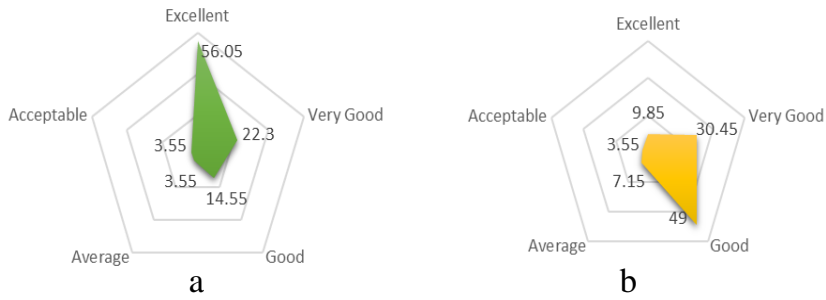

Figure 10: Questions Result Chart. (a)Question 3. (b)Question 5.

\subsection{Methodology Effectiveness Measurement}

To evaluate the learning methodology effectiveness, quantitative measurements performed to analyze the effectiveness using statistical tests. Two measurements performed to test students' learning level of knowledges and students' learning skills.

First of all, t-test hypothesis statistical test performed to compare quantitative measurements result of the proposed method and the classical method. In statistic, it is impossible to prove that something right but it is possible to prove that something wrong [18]. From this concept, a t-test hypothesis performed to test that there are no differences between the result of proposed education method and the classical method. A three hours exam performed to collect the hypothesis test data. The exam measured two different knowledges parts. first part, knowledge learned through the proposed learning methodology. Second, knowledge learned through the classical conventional education method. The two parts have the same weight degree in the exam, sixty degrees for each part. The questions consist from calculation questions (20\%), design questions (40\%), answer questions (20\%), and programing questions (20\%). The hypothesis test applied on the exam scores result in the following: the $t$ state value (3.53) for the test greater than the $t$ critical (2.14). also, the p-value (0.003) smaller than the alpha value (0.05). As a result, there is significant differences between the two methods results. Also, the mean value result for the proposed method 42.6 had greater than the result from the classical method 33.73. the significant difference and the greater mean value for the proposed method indicated statistical evidences of much higher learning performance of the hybrid spiral project based learning method than the classical method. Hypothesis test results shown in table 4. Most of the students score improved while using the proposed method. Figure 11 show sample results of students' scores.

Table 4: t-test Hypothesis Statistical Test Results.

\begin{tabular}{|c|c|c|}
\hline Measurement & $\begin{array}{c}\text { Classical } \\
\text { method }\end{array}$ & $\begin{array}{c}\text { Proposed } \\
\text { method }\end{array}$ \\
\hline Mean & 33.73333333 & 42.6 \\
\hline Variance & 56.4952381 & 82.82857143 \\
\hline t Stat & \multicolumn{2}{|c|}{3.53693384} \\
\hline P(T<=t) two-tail & \multicolumn{2}{|c|}{0.003285081} \\
\hline t Critical two-tail & \multicolumn{2}{|c|}{2.144786688} \\
\hline
\end{tabular}

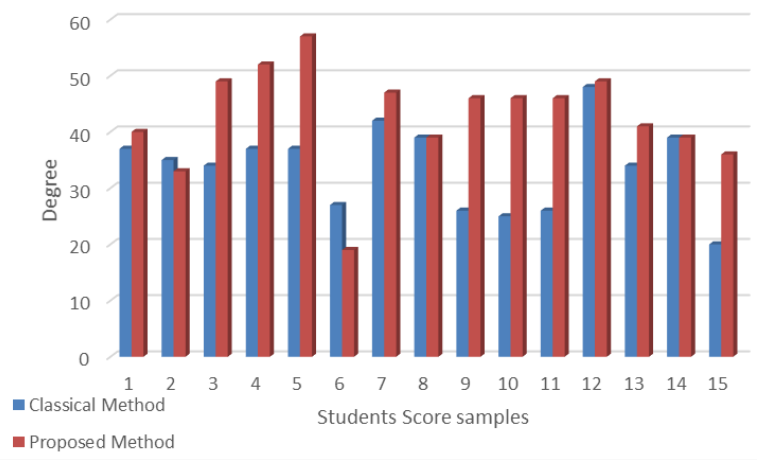

Figure 11: Students samples Score.

Second measurement performed to measure students learning skills. Students learning skills evaluated by examining the projects outcomes. All the results shown efficient use of the course skills. Furthermore. a statistical test performed to correlate students' final exams scores and the final projects scores. Person correlation coefficient test performed on the data and the score is $(0.799)$. This score shows strong positive correlation between exams and projects. Which it indicates tight coupled between skills learning and the knowledge level learning in the proposed hybrid spiral project based learning.

Finally, all the measurement performed indicate the effectiveness of the proposed method in educational microprocessor course and other engineering courses.

\section{CONCLUSION}

This paper proposed hybrid educational method named "hybrid spiral project based learning method" for engineering educational courses. This paper investigates the impact of the proposed method on students learning microprocessor course to illustrate the method. Where the course teaches using spiral method and project based learning. Statistical tests analysis validates the method and provide evidence about the improvement in knowledge and skills learning. I recommended to use this model in other engineering courses. 


\section{REFERENCE}

[1] A. Selvaggio, A. Sadiki, T. R. Ortelt, R. Meya, C. Becker, S. Chatti, et al., "Development of a cupping test in remote laboratories for engineering education," in 2016 13th International Conference on Remote Engineering and Virtual Instrumentation (REV), 2016, pp. 122-126.

[2] D. May, C. Terkowsky, T. R. Ortelt, and A. E. Tekkaya, "The evaluation of remote laboratories: Development and application of a holistic model for the evaluation of online remote laboratories in manufacturing technology education," in 2016 13th International Conference on Remote Engineering and Virtual Instrumentation (REV), 2016, pp. 133-142.

[3] S. V. Tagliacane, P. W. C. Prasad, G. Zajko, A. Elchouemi, and A. K. Singh, "Network simulations and future technologies in teaching networking courses: Development of a laboratory model with Cisco Virtual Internet Routing Lab (Virl)," in 2016 International Conference on Wireless Communications, Signal Processing and Networking (WiSPNET), 2016, pp. 644649.

[4] Muchlas and M. A. Novianta, "An online lab for digital electronics course using information technology supports," in 2015 International Conference on Science in Information Technology (ICSITech), 2015, pp. 299-302.

[5] M. S. Matijević, N. D. Jović, M. S. Nedeljković, and Đ. S. Čantrak, "Remote labs and problem oriented engineering education," in 2017 IEEE Global Engineering Education Conference (EDUCON), 2017, pp. 1391-1396.

[6] V. F. Martins, P. N. M. Sampaio, A. J. A. Cordeiro, and B. F. Viana, "Problem-based learning methodology applied within a data network infrastructure design course a real case implementation," in 2017 12th Iberian Conference on Information Systems and Technologies (CISTI), 2017, pp. 1-6.

[7] S. C. d. Santos, "PBL-SEE: An Authentic Assessment Model for PBL-Based Software Engineering Education," IEEE Transactions on Education, vol. 60, pp. 120-126, 2017.

[8] G. Verbič, C. Keerthisinghe, and A. C. Chapman, "A Project-Based Cooperative Approach to Teaching Sustainable Energy Systems," IEEE Transactions on Education, vol. 60, pp. 221-228, 2017.

[9] F. Martinez-Rodrigo, L. C. H.-D. Lucas, S. d. Pablo, and A. B. Rey-Boue, "Using PBL to Improve Educational Outcomes and Student Satisfaction in the Teaching of DC/DC and DC/AC Converters," IEEE Transactions on Education, vol. 60, pp. 229-237, 2017.

[10] W. A. Balid, Mahmoud, "A Novel FPGA Educational Paradigm using the Next Generation Programming Languages, Case of an Embedded Systems Course," IEEE Global Engineering Education Conference, 2013.
[11] F. M. Fahimeh Veladat "Spiral learning teaching method: Stair stepped to promote learning," Procedia - Social and Behavioral Sciences, 2011.

[12] S. Vemuru, S. Khorbotly, and F. Hassan, "A spiral learning approach to hardware description languages," in 2013 IEEE International Symposium on Circuits and Systems (ISCAS2013), 2013, pp. 2759-2762.

[13] G. Joshi and P. Desai, "Building Software Testing Skills in Undergraduate Students Using Spiral Model Approach," in 2016 IEEE Eighth International Conference on Technology for Education (T4E), 2016, pp. 244-245.

[14] L. Jing, Z. Cheng, J. Wang, and Y. Zhou, "A Spiral Stepby-Step Educational Method for Cultivating Competent Embedded System Engineers to Meet Industry Demands," IEEE Transactions on Education, vol. 54, pp. 356-365, 2011.

[15] D. C. Panda, "Teaching electromagnetic theory with spiral curriculum approach to undergraduates," in 2013 IEEE Applied Electromagnetics Conference (AEMC), 2013, pp. $1-2$.

[16] L. K\&H MFG. CO. (Available Online in Aug/2017). MTS-86C 8086 Microcomputer Trainer. Available: http://www.kandh.com.tw/products 2.php?prod=205

[17] L. E. Ltd. (Available Online Aug / 2017). Proteus Design Suite Available: https://www.labcenter.com/

[18] D. C. Howell, Fundamental Statistics for the Behavioral Sciences Duxbury Press, 1999. 